\title{
Paris em quatro estações
}

Jane Pinheiro de Freitas ${ }^{1}$

Os mundos das pessoas têm tamanhos e rostos diferentes, podem ser a rua onde se mora, a cidade, o pais, a Terra, podem até ser os mundos além-mundo. ${ }^{2}$

\section{Desenhando as pétalas do caminho}

Com os primeiros sinais de luz avisto pelo vidro uma cidade bem desenhada, dividida com minúcia em bairros numerados, o aeroporto com nome de presidente mostra a imponência da cidade sonhada como cenário de comemorações amorosas, prêmios de grandes concursos, destino de viajantes de todo o mundo, la ville lumière para orgulho dos seus habitantes. Mas não ares de boa recepção no rosto do homem sério que carimba meu passaporte e para quem tenho que justificar a permanência na cidade, começo então a sentir qual o retrato da Paris que me espera: pesquisas, seminários em universidades, visitas a bibliotecas, assim vou respondendo ao rápido questionário e logo me preparando para atravessar as enormes portas que me separam da entrada na cidade.

Ao pegar as malas me dou conta de que também não será a cidade que havia visitado há três anos em estado de encantamento

1 Doutoranda em cotutela entre a FFLCH/Universidade de São Paulo e a CRIMIC/Universidade Sorbonne-Paris IV. Pesquisa de tese: "Visões do (des)encanto: estudo sobre a representação social do feminino em Clarice Lispector e Maria Judite de Carvalho”. Bolsista CAPES, email: janepinheiro@usp.br

2 CARVALHO, Maria Judite de. Este tempo. Lisboa: Caminho, 1991, p. 24. 
pelas descobertas, agora o que vejo é uma Paris bela mas sob o peso da imigração e sem braços de redentor. Na multidão o idioma francês apequena-se em meio a tantas outras línguas, rostos variados e agitados no imponente Charles de Gaulle já dão a notícia de que a França de Sarkozy perdeu a diplomacia iluminista, e que os estrangeiros são olhados como possíveis imigrantes. A companhia de amigos franceses, vindos de longínqua região parisiense para me encontrar, dá-me um certo conforto e a ilusão do acolhimento. Pelas ruas ainda há algum cinza deixado pelo intenso inverno, mas que a primavera recém- chegada trata de cobrir com suas belas flores pulsantes, com os olhos atentos me abandono na visão dos boulevards que mostram franceses quase sorridentes em suas Velibs ${ }^{3}$, en pleine liberté, então confirmo o dito em minhas aulas de francês: o humor deles tem relação com as condições climáticas. A mim também encanta ver o sol refletir-se nas águas do Sena e estender-se pelas belas pontes sobre o rio por onde vão e vêm as barcas turísticas.

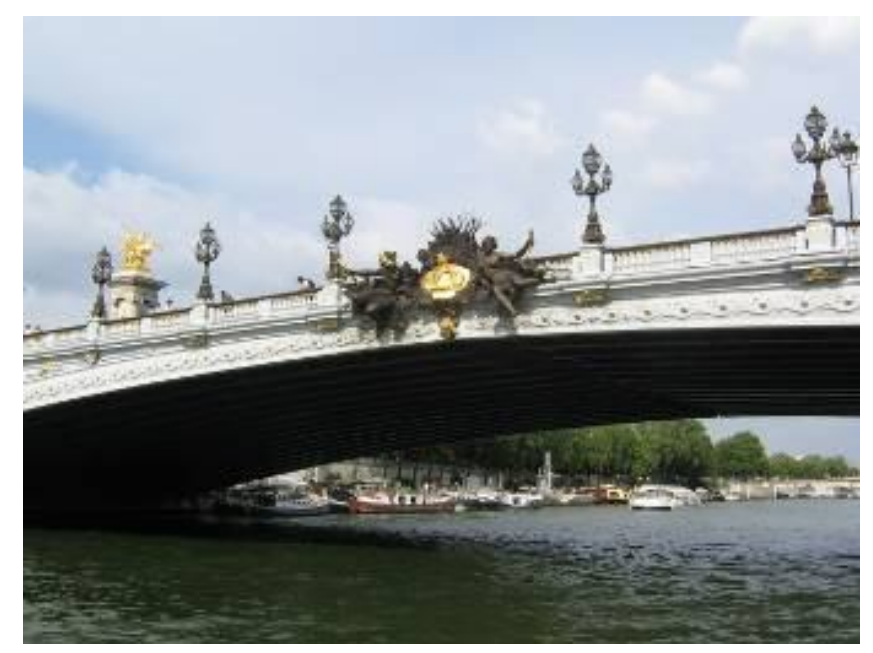

Fig. 1. Ponte Alexandre III, atravessa o rio Sena à altura dos Invalides

A chegada na Cidade Universitária foi surpreendente pela beleza daquele conjunto de prédios-países, cada um com sua particularidade, a casa do Brasil podia ser vista de longe com seus tons em verde e

${ }^{3}$ Sistema de bicicletas oferecidas como transporte público pela prefeitura Paris. 
amarelo inseridos na arquitetura de Lucio Costa. O espaço é cuidadosamente zelado em todo o prédio de cinco andares, cada ambiente valoriza a cor local e a arte feita em nossas terras; estamos cercados por Índia, Noruega e Portugal, as casas que fazem fronteira com a nossa parecem ter admiração pela "cor local" em harmonia com o tom pastel tão reverenciado pela Europa.

A semana que me esperava seria aquela na qual eu deveria descobrir a França dos imigrantes, dos sens papiers, dos que precisam se instalar e viver um tempo pra lá dos passeios turísticos. Situações burocráticas em curso, eu deveria visitar o gabinete de minha coorientadora na Universidade Sorbonne-Paris IV, logo à porta sou surpreendia por dois "gentis" senhores em uniforme autoritário, pedemme documento de identificação, eu timidamente mostro-lhes a carta de Madame Besse que me esperava, deixam-me entrar, mas sem escapar ao olhar de receio que me corta de cima para baixo. Corredores escuros e labirínticos me levam a ela, e sua calma e acolhimento me fazem esquecer do medo que lhe antecedeu, a conversa se passa bem, mas saio de lá com a indicação de três bibliotecas que deverei procurar e de alguns títulos para leitura urgente, não há mais tempo de pensar na terra distante, é preciso arregaçar mangas e enfrentar as tradicionais bibliotecas francesas, entre elas a Nacional e a da Sorbonne, onde só terei acesso após o sistema burocrático de confecção de uma carte de letrice, feita a primeira carteira, parto para um lugar que se tornaria muito especial para mim.

\section{Entre gênero e escrita}

É Marguerite Durand, a importante jornalista e militante feminista, que dá nome a uma das bibliotecas mais particulares de Paris, onde está abrigado o maior dos acervos franceses de literatura, crítica e teoria sobre o feminino. Já no elevador o aviso: "Exclusivo para 
pesquisas sobre o feminino", no corpo funcional apenas mulheres, todas determinadas e mostrando sempre um certo orgulho por fazerem parte daquela instituição que lhes dá a regalia de trabalharem apenas 4 horas por dia. Ao chegar na pequena mesa de recepção senti que as mulheres me olhavam como se quisessem ler em minha expressão a seriedade da pesquisa, após analisarem a documentação formada pelas várias cartas com as quais eu me apresentava finalmente me entregaram a carteira de pesquisadora de estudos femininos, e um código que me daria acesso ao rico acervo da biblioteca. Começo então minha aventura pelos tantos títulos, tudo via sistema eletrônico, os livros ficavam em vários andares longe dos leitores e chegavam até à sala de leitura por meio de um antigo elevador exclusivo para as obras; tudo que me havia sido indicado estava ali. Esse passou a ser o lugar onde ficaria durante minhas tardes de primavera parisiense, felizmente havia uma grande parede de vidro por onde era possível ver a paisagem da rue de Tolbiac, com seus passeios floridos, assim fica-se dentro com a impressão de estar de fora.

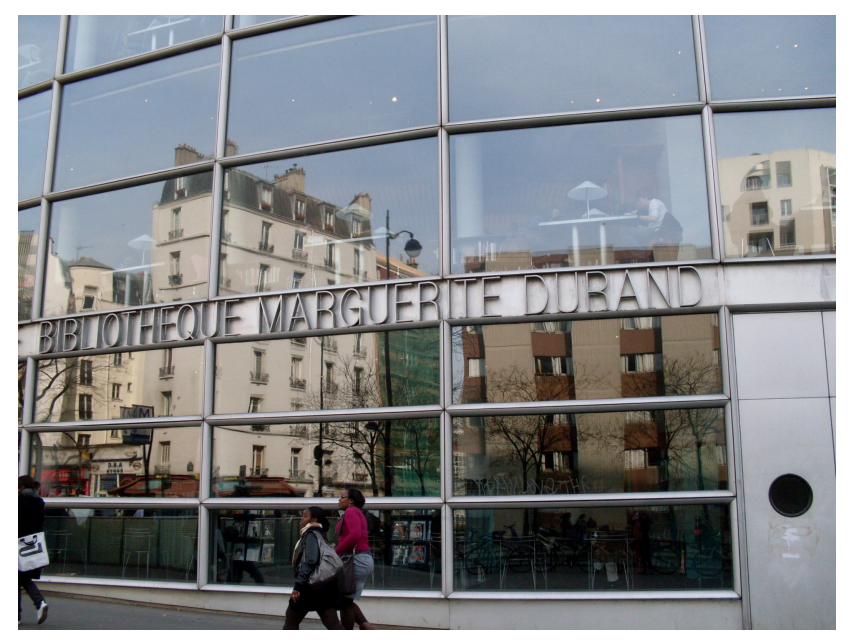

Fig. 2. Vista lateral do prédio da Biblioteca Marguerite Durand

Após alguns dias no sítio destinado aos estudos femininos, aventuro-me na minha segunda empreita: a Blibiothèque National de France, de longe avisto as grandes torres em forma de livro que dominavam a paisagem da Avenue de France, no primeiro dia de visita 
já descobri que ali estava um dos maiores acervos de livros do mundo, onde tudo funcionava através de um sistema de relações frias e robóticas no qual tudo era feito eletronicamente, nem mesmo na reserva de livros tínhamos contato com as pessoas. No entanto o funcionamento impecável da gigante biblioteca nos fazia esquecer a falta de contato humano, nas salas com mais de duzentos leitores era possível ouvir o mínimo balbucio o qual logo era repreendido pela atenta administração da sala. Como um imenso porão literário, a sala de leitura ficava vários metros abaixo do nível da rua, lá só chegavam os pesquisadores credenciados e com sua carte de chercheur, além de ser obrigatória a reserva de lugares. Entre as leituras, os cafés com suas portas antirruídos davam a impressão de se estar numa imensa sala de debates onde idéias variadas eram discutidas pela intelectualidade francesa, lá eu tinha medo de falar meu francês ainda com sotaque dos trópicos, preferia não me aventurar e me limitava a pedir meu petit café e em uma pequena mesa respirar o cheiro das discussões.

\section{O sol a apropriar-se da noite}

Do lado de fora das bibliotecas a primavera despede-se sob o sol do verão, os dias começam a se alongar de maneira impressionante confundindo-se com a noite, comecei a me dar conta de que jantava com a cozinha ensolarada em plena $21 \mathrm{~h}$, as jornadas pareciam não ter fim, e as horas noturnas iam diminuindo cada vez mais, então percebi porque aquele povo, com reputação de mal-humorado, andava rindo pelas ruas, e se cumprimentando nos sinais de trânsito. Via todas as manhãs uma Paris aquecida e imponente, bela e pulsante, imagem que deixava a nós estudantes com vontade de abraçar a vida, o calor valorizado em cada gota dos longos dias, os parques tinham seus gramados repletos na hora do almoço, cafés com terraços fervilhantes e rostos avermelhados ao sol. 
Chega então um dos dias mais esperados para os franceses: La fête de la musique, um dia por ano em que a França se transforma em palco de músicos amadores e profissionais. Paris é o centro da agitação musical nesse dia mais longo do ano, no qual o sol se estenderá até às 23h para alegria dos boêmios. Parques, praças e ruas tomadas por cantores de jazz, chanson française e ainda os ritmos africanos, a velha Bastille abriga o maior número de pessoas, as vagas nos cafés tornamse verdadeiros prêmios de loteria, e os passeios e bancos públicos vão sendo tomados pela multidão. Cruzando a cidade de sul a norte percebi como aquele dia era importante para o orgulho parisiense, todos estavam na rua e tinham prazer em percorrer a festa da música entre amigos ou família. Saint-German-des-Près estava sonora e repleta de saxofones, clarinetes, baixos e músicos de vários países da Europa que sustentavam a boa fama do bairro que além de ser o espaço dos existencialistas Beauvoir e Sartre, era visto também como lugar de blues e jazz em Paris. No Sacre-coeur, as ruas estreitas eram tomadas por músicos e bandas que cantavam a França de Piaf e Aznavous diante de turistas eufóricos.

A temporada turística instaura-se, durante meus trajetos de pesquisa vejo que alguns parisienses esquecem o bom tempo e protestam nos metrôs superlotados de americanos, japoneses, chineses com máquinas fotográficas empunhadas e sorriso brilhante dentro das camisetas 'I love Paris', um certo insulto para um povo protecionista da cultura e do idioma como identidades nacionais. Foi em meados do verão que comecei as pesquisas no Centro Cultural Calouste Gulbenkien ${ }^{4}$, para chegar até lá era preciso passar pelo Arco do Triunfo, principal atrativo dos turistas, lugar de honra para os soldados-heróis da França de tantas guerras, era preciso cautela ao passar driblando os cenários das fotos disputadas pelos tantos visitantes do lugar, famílias inteiras se entesavam diante do arco para serem fotografadas. Um dia,

${ }^{4}$ Centro de Cultura e Literatura Portuguesas, onde se localiza uma grande biblioteca e sala de estudos. 
com mais tempo, sentei-me em um banco a observar um chinês de olhar morto e solitário que preparou sua câmera de última geração, se colocou bem diante da lente e ensaiou um sorriso sem hábito dando tom artificial ao rosto de músculos sérios, depois se instalou ao meu lado no banco e disparou de novo sua câmera automática, sem mesmo perguntar se eu aceitava mascarar sua solidão, lembrei-me da sociedade da aparência tão bem citada nas crônicas de Maria Judite de Carvalho, autora pela qual eu estava naquele sítio de pesquisas.

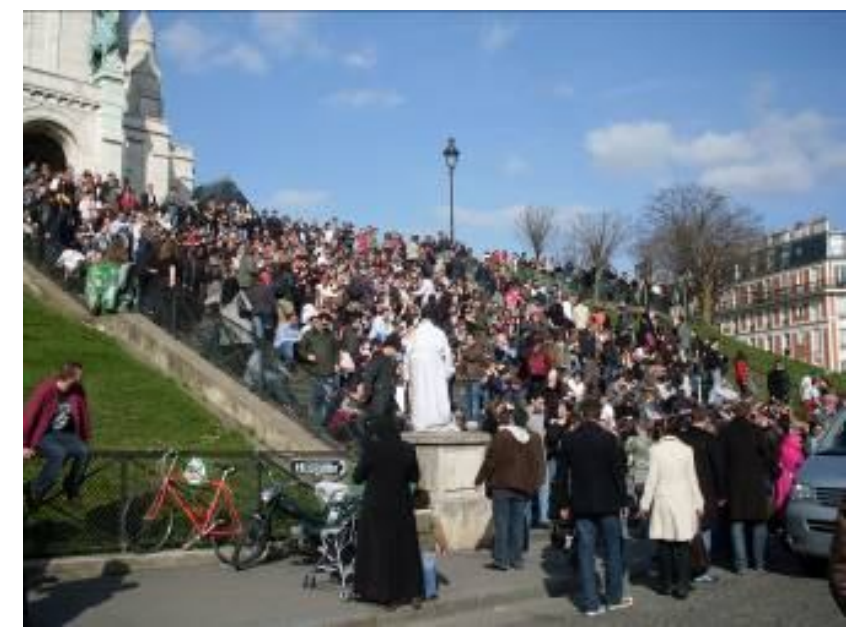

Fig. 3. Show de músicos marroquinos nas escadarias do Sacre-coeur

Nas ruas, ia me aventurando cada vez mais na tentativa de romper a rigidez dos franceses, foi assim que um dia iniciei conversa com uma senhora quase centenária que empolgou-se ao saber que eu estava ali para estudar aspectos do feminino, surpreendeu-se também quando eu lhe disse que no Brasil muitas mulheres avançavam seus estudos até o Doutorado, ela havia ido apenas até o Baccalauréat ${ }^{5}$ mas era leitora de quase trinta livros por ano, interrogou-me bastante sobre minha pesquisa, contei-lhe os detalhes enquanto ela me ouvia atentamente e logo após perguntou-me com ar questionador: Vous pouvez me dire a quoi tout ça sert? Les gens du pouvoir feront quoi par

${ }^{5}$ Exame nacional que finaliza os estudos secundários e dá acesso às universidades francesas. 
les femmes iletrées, ouvrières, etc? ${ }^{6}$. Tive que deixá-la para correr ao meu destino, mas fiquei vários dias refletindo sobre suas questões. No entanto aquele era um dia muito importante, e eu caminhava para a casa de Claudine Monteil, estudiosa de Simone de Beauvoir e do feminismo francês, para entrevistá-la.

Fui surpreendida desde a chegada no prédio com arquitetura dos anos trinta e localizado diante do Cemitério de Montparnasse onde estão sepultados Sartre e Beauvoir. Madame Monteil me encontra ao portão, com sorriso largo e movimentos rápidos, gênero nada comum à personalidade francesa, convida-me a acompanhá-la até a boulangerie onde compramos croissants para acompanhar o bom chá que nos esperava em seu apartamento. Ambiente acolhedor com uma sala repleta de livros e quadros que logo vejo são assinados por Hélène de Beauvoir ${ }^{7}$. A gentileza e simpatia de Claudine me fazem esquecer a imensa ilha solitária que me tem sido cada francês até então, sou convidada a sentar em uma bela poltrona pertencente aos belos móveis dos anos vinte, quando me instalo descubro que a mesma pertenceu a Simone de Beauvoir sendo umas das principais peças de seu apartamento que ficava a alguns metros dali.

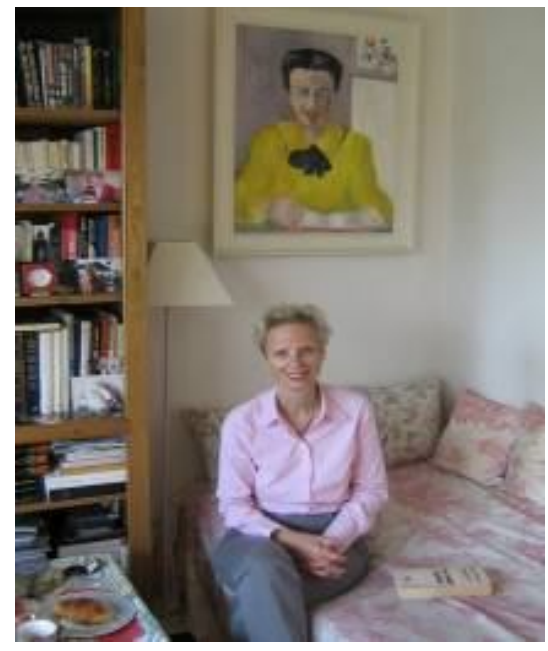

Fig. 4. Claudine Monteil na sala de seu apartamento em Paris

${ }^{6}$ A senhora pode me dizer a que serve tudo isso? As pessoas do poder farão o que pelas mulheres analfabetas operárias, etc?

${ }^{7}$ Irmã mais nova de Simone de Beauvoir e amiga íntima de Claudine Monteil. 
Durante uma tarde agradável ouço histórias surpreendentes sobre a relação de Sartre e Simone de Beauvoir, além de detalhes sobre o círculo de intelectuais que compunha a reputada revista Les Temps Modernes dirigida oficialmente por Jean-Paul Sartre mas que sempre teve Simone de Beauvoir em sua direção. É empolgante a maneira como Claudine Monteil descreve a personalidade das mulheres que compunham o MLF (Mouviment pour la libération des femmes) nos anos 60 em Paris, tendo como conselheira intelectual Simone de Beauvoir, elas decidiam juntas grandes movimentos de reivindicação, como a passeata pelo direito ao aborto em 1975, assim cada uma contribuía com sua capacidade intelectual e reivindicadora para construir um novo feminino. Entre essa e outras experiências acadêmicas me convenço de que estou em um grande centro de estudos sobre a mulher, e sobre l'écriture féminine ${ }^{8}$. Ao deixar o apartamento de Madame Monteil, no início da noite, senti bater em meu rosto contente os primeiros ventos do outono.

\section{Folhas caidas entre fatos novos}

As aulas e seminários ganham o ritmo de início de ano letivo, em meio a colóquios e conferências apresentadas diariamente nas várias universidades de Paris, vejo que terei um semestre agitado, mas dentro de minhas possibilidades de dedicação exclusiva à pesquisa isso não seria tão difícil. Parto para fazer a reunião mensal com minha coorientadora e depois de conversarmos sobre tudo que eu havia feito de pesquisas nos últimos meses chegamos à conclusão de que de fato eu havia redesenhado meu trabalho a partir das tantas informações e novos estudos encontrados em Paris, e que ainda havia muito a fazer. Foi então que ela me sugeriu que passasse de um estágio doutoral para

8 O termo foi criado pela crítica feminista em meados dos anos 60. 
um doutorado em cotutela, o que me daria também direito a um diploma francês e responderia melhor aos novos rumos da pesquisa. $O$ trabalho era grande e eu só tinha uma semana para preparar o dossiê exigido pela Sorbonne, só então eu pude descobrir o que é uma burocracia francesa em toda a sua excelência; mas com a ajuda das orientadoras do Brasil e da França, e o trabalho de madrugadas, tudo ficou pronto e minha pesquisa francesa passava a ter novos rumos.

Nas ruas o humor dos franceses ganha nuances de frio, já não há mais as manhãs ensolaradas e o vento derruba a cada dia mais folhas pelas calçadas parisienses, os dias começam a diminuir, o sol já não é o mesmo e se vai mais cedo, a crise econômica se instala entre os franceses, soma-se aos impostos e ao medo do futuro, começam os vestígios de suicídio, constato então que o povo habituado a liberté e fraternité não tem muito fôlego para sofrimentos. Entre as caras fechadas e a pouca tolerância com estrangeiros, Paris começa a mudar de cor.

Continuo minhas pesquisas agora com uma pequena viagem a Lisboa, como resposta a antiga amizade que mantém com minha coorientadora, o escritor Urbano Tavares Rodrigues aceitou receber-me em sua casa para falar de seus anos com Maria Judite de Carvalho, a escritora que é parte de meu objeto de pesquisa. Entre minha chegada a Lisboa e a ida ao apartamento do escritor, aventurei-me nas ladeiras do Chiado e pude passar diante dos poetas que ainda hoje marcam a história de Portugal, Camões e Pessoa, como se do bronze falassem seus versos às multidões. O encontro com Urbano Tavares trouxe-me não só as informações que precisava sobre Maria Judite, mas duas horas de um aprendizado que poderia se estender por uma vida, é com os olhos cheios de lembranças que confessa ter sido a esperança no 25 de abril sua motivação à luta, admirava muito a personalidade de sua companheira de anos, e a descreveu sensivelmente: 
Ela tinha uns olhos de muita ironia quando observava ou descrevia a sociedade, via detalhes que a deixavam chocada, mas ao mesmo tempo possuía uma ternura bonita pela vida e grande respeito pelos acontecimentos ao seu redor. Era cética e pessimista em relação a mudanças políticas, e nunca acreditou no 25 de abril, no entanto conseguia ter bom humor e esperança quando estava com os amigos. Lembro que ela andava pelos autocarros sempre a observar como quem pesquisa a vida humana, ou está a testar o êxito das relações entre as pessoas. ${ }^{9}$

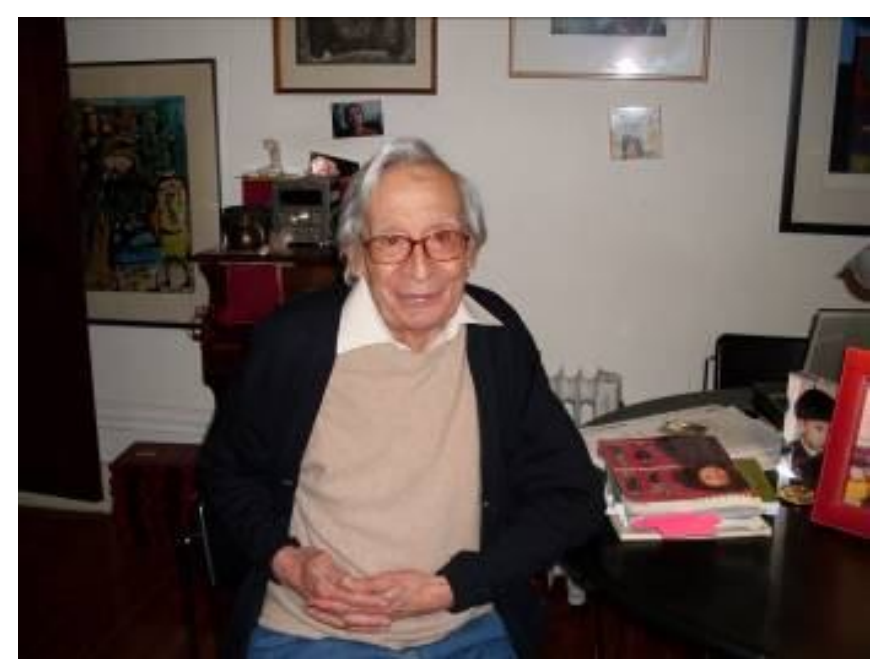

Fig. 5. O escritor Urbano Tavares Rodrigues em seu apartamento em Lisboa

\section{Et la neige viens...}

Os aquecedores começam a se instalar nos cafés de São Michel, os terraços já não estão repletos, a publicidade avisa aos franceses que se previnam contra os perigos de gripe e de outras mazelas do frio, as vitrines de Champs Elisée começam a mostrar seus pesados casacos.

\footnotetext{
${ }^{9}$ Entrevista concedida por Urbano Tavares Rodrigues, em Lisboa 22/10/2008.
} 
Nas universidades as conversas dos corredores apontam para a grande greve que virá com os primeiros dias de 2009. O semestre termina ameaçado pela incerteza de como acontecerá o próximo, os ânimos são calmos e a neve ultrapassa as previsões, trazendo consigo o presságio de que teremos um doloroso inverno. Começo a me convencer de que o melhor é evitar as ruas, as calçadas cobertas de gelo são um grande desafio para toda a casa do Brasil. Os meses vividos e as pesquisas feitas são forçados a caber em minhas malas que começam a guardar a volta às terras brasileiras, e já sem medo de uma conversa com os franceses, então me aventuro pelas ruas brancas de Paris para tentar conhecer um pouco mais da sociedade descrita por Balzac. Descubro então uma França que já não sonha com o sol, mas que tem como matéria prima de suas preocupações a possibilidade de um amanhã com tranquilidade e sem solidão, esse é o povo que não tive olhos pra ver em três estações.

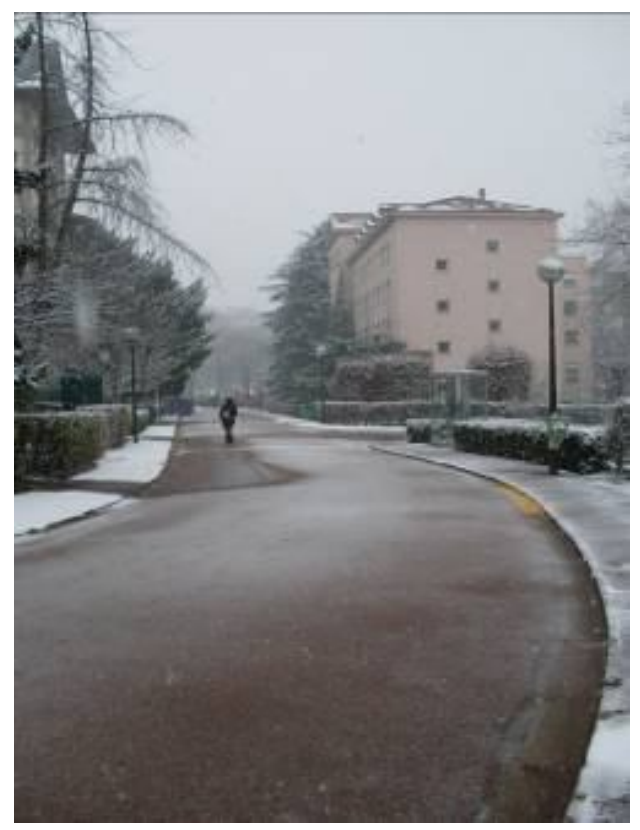

Fig. 6. Saída da Cidade Universitária de Paris 